\title{
Diabetes-induced changes in lens antioxidant status, glucose utilization and energy metabolism: effect of DL- $\alpha$-lipoic acid
}

\author{
I. Obrosova, X. Cao, D.A. Greene, M.J.Stevens \\ Division of Endocrinology and Metabolism, Department of Internal Medicine, University of Michigan Medical Center, \\ Ann Arbor, Michigan, USA
}

\begin{abstract}
Summary The study was aimed at evaluating changes in lens antioxidant status, glucose utilization, redox state of free cytosolic NAD(P)-couples and adenine nucleotides in rats with 6-week streptozotocin-induced diabetes, and to assess a possibility of preventing them by DL- $\alpha$-lipoic acid. Rats were divided into control and diabetic groups treated with and without DL- $\alpha$-lipoic acid $\left(100 \mathrm{mg} \cdot \mathrm{kg}\right.$ body weight ${ }^{-1} \cdot$ day $^{-1}$, i.p.). The concentrations of glucose, sorbitol, fructose, myo-inositol, oxidized glutathione, glycolytic intermediates, malate, $\alpha$-glycerophosphate, and adenine nucleotides were assayed in individual lenses spectrofluorometrically by enzymatic methods, reduced glutathione and ascorbate - colorimetrically, and taurine by HPLC. Free cytosolic NAD ${ }^{+} \mathrm{NADH}$ and $\mathrm{NADP}^{+}$:NADPH ratios were calculated from the lactate dehydrogenase and malic enzyme systems. Sorbitol pathway metabolites were found to increase, and antioxidant concentrations were reduced in diabetic rats compared with controls. The profile of glycolytic intermediates (increase in glucose 6-phosphate and fructose 6-phosphate, decrease in fructose1,6diphosphate, increase in dihydroxyacetone phos-
\end{abstract}

Received: 10 November 1997 and in final revised form: 5 June 1998

Corresponding author: Dr. I. Obrosova, Division of Endocrinology and Metabolism, Department of Internal Medicine, 1150 West Medical Center Drive, MSRB II, Rm 5570, Ann Arbor, Michigan 48109-0354, USA

Abbreviations: GSH, Reduced glutathione; GSSG, oxidized glutathione; G6P, glucose 6-phosphate; F6P, fructose 6-phosphate; FDP, fructose 1,6-diphosphate; DHAP, dihydroxyacetone phosphate; 3-PG, 3-phosphoglycerate; PEP, phosphoenolpyruvate; $\alpha$-GP, $\alpha$-glycerophosphate; BSO, L-buthionine $(\mathrm{S}, \mathrm{R})$-sulphoximine. phate, 3-phosphoglycerate, phosphoenolpyruvate, pyruvate, and no change in lactate), and 5.9-fold increase in $\alpha$-glycerophosphate suggest diabetes-induced inhibition of glycolysis. Free cytosolic NAD ${ }^{+}$:$\mathrm{NADH}$ ratios, ATP levels, ATP/ADP $\times$ inorganic phosphate $\left(\mathrm{P}_{\mathrm{i}}\right)$, and adenylate charge were reduced in diabetic rats while free cytosolic $\mathrm{NADP}^{+}: \mathrm{NADPH}$ ratios were elevated. Diabetes-induced changes in the concentrations of antioxidants, key glycolytic intermediates, free cytosolic $\mathrm{NAD}^{+}: \mathrm{NADH}$ ratios, and energy status were partially prevented by DL- $\alpha$-lipoic acid, while sorbitol pathway metabolites and free cytosolic $\mathrm{NADP}^{+}$:NADPH ratios remained unaffected. In conclusion, diabetes-induced impairment of lens antioxidative defense, glucose intermediary metabolism via glycolysis, energy status and redox changes are partially prevented by DL- $\alpha$-lipoic acid. The findings support the important role of oxidative stress in lens metabolic imbalances in diabetes. [Diabetologia (1998) 41: 1442-1450]

Keywords Lens, streptozotocin-diabetic rat, DL- $\alpha$-lipoic acid, sorbitol pathway, redox and energy status
According to the data of the National Diabetes Data Group [1], the prevalence of cataracts - one of the major ocular disorders in patients with diabetes mellitus - is at least $50 \%$ higher in both Type I (insulindependent) diabetes mellitus and Type II (non-insulin-dependent) diabetes than in corresponding agematched non-diabetic subjects. Sugar cataractogenesis is initiated by osmotic stress caused by intralenticular accumulation of polyols produced by the enzyme aldose reductase [2-6]. Although growing evidence indicates the key role of an osmotic mechanism in the sequelae of biochemical and morphological chan- 
ges leading to sugar cataract formation [7, 8], some recent studies also suggest that cataracts can be exacerbated by non-enzymatic glycation of lens proteins [9] and other factors. The importance of oxidative stress in various types of experimentally induced cataractogenesis is well established [10] but its role in diabetes-induced cataractogenesis remains a subject of debate. Some reports indicate an important role for oxidative damage in the onset and progression of diabetic cataracts [11], but others failed to demonstrate any substantial retardation of post-translational modification of lens crystallins [12] or cataract formation [13] with antioxidant therapy. At the same time, numerous studies in models of diabetes and galactosaemia suggest that the loss of major antioxidants such as reduced glutathione (GSH), taurine, and ascorbate is a result of osmotic compensation [14-16].

A role for changes in intermediary and energy metabolism in diabetes-induced cataractogenesis remains unclear. According to Hothersall et al. [17], energy deficiency can contribute to certain lenticular changes (i. e. impairment of membrane transport, glycoprotein and proteoglycan biosynthesis) in diabetes. Diabetes-induced impairment in lens energy status could at least in part result from the inhibition of glycolysis as it is known that $70 \%$ of ATP in the lens derives from the glycolytic pathway [18]. One of the glycolytic enzymes, glyceraldehyde-3-phosphate dehydrogenase, was found to be particularly vulnerable to oxidative damage [19], which could impede the flux through the lower segment of glycolysis in the diabetic lens. It is reasonable to assume that other lenticular enzymes of intermediary and energy metabolism can also be affected by diabetes-induced oxidative stress (resulting from the loss of major antioxidants), and that these changes can be prevented by antioxidant therapy.

The purpose of the present study was to examine changes in the antioxidant status, glucose utilization in the glycolytic pathway, redox state of NAD(P)couples, and adenine nucleotide system in lens in rats that have been diabetic for 6 weeks, and the possibility of their prevention with DL- $\alpha$-lipoic acid. It is known from in vitro studies [20] that both DL- $\alpha$-lipoic acid as well as its $\mathrm{R}$ - and $\mathrm{S}$-enantiomers penetrate into the lens and are reduced to dihydrolipoate, a potent antioxidant scavenging hydroxyl, superoxide, and peroxyl radicals, as well as singlet oxygen, and regenerating other antioxidants including GSH, ascorbate, and vitamin $\mathrm{E}[21,22]$. The ability of $\alpha$-lipoic acid to prevent the depletion of major antioxidants and to restore the antioxidative defense enzyme activities has been demonstrated in a number of oxidative stress models including L-buthionine(S,R)-sulphoximine (BSO)-induced cataract $[22,23]$.

\section{Materials and methods}

The experiments were performed in accordance with regulations specified by the National Institutes of Health "Principles of Laboratory Animal Care, 1985 revised version" and University of Michigan Protocol for Animal Studies.

Animals. The experiments were performed on barrier-sustained, Caesarean-delivered male Wistar rats body weight 250-300 g, fed a standard rat chow diet (ICN Biomedicals, Cleveland, Ohio, USA) and divided into the following groups: 1) control group; 2) control group treated with DL- $\alpha$-lipoic acid (Sigma Chemical Co., St. Louis, Mo., USA), at a dose of $100 \mathrm{mg} \cdot \mathrm{kg}^{-1} \cdot$ body weight ${ }^{-1} \cdot$ day $^{-1}$, intraperitoneally; 3) diabetic group with 6-week duration of diabetes; 4) diabetic group with 6-week duration of diabetes, treated with DL- $\alpha$-lipoic acid as described in 2) above. Diabetes was induced by a single intraperitoneal injection of streptozotocin $(55 \mathrm{mg} / \mathrm{kg}$ body weight).

Reagents. Unless otherwise stated, all chemicals were of reagent-grade quality, and were purchased from Sigma. Methanol (HPLC grade), perchloric acid, hydrochloric acid, and sodium hydroxide were purchased from Fisher Scientific (Pittsburgh, Pa., USA) Ethyl alcohol (200 proof dehydrated alcohol, U.S.P. punctilious) was purchased from Quantum Chemical Co, (Tiscola, Ill., USA). Dihydroxyacetone phosphate dilithium salt monohydrate was purchased from Fluka BioChemika (Buchs, Switzerland). B-D-Glucose, sorbitol, N.F., myo-inositol, C.P., and D-fructose, U.S.P. were purchased from Pfanstiehl Laboratories (Inc., Waukegan, Ill., USA).

Experimental procedure. Rats from each group were anaesthetised with i.p.urethane (1-1.2 g/kg)(Sigma) and subsequently killed by cervical dislocation. Both lenses were rapidly dissected by posterior incision, carefully separated from any accompanying aqueous and vitreous humours by gentle rolling over a fine filter paper, and frozen in liquid nitrogen for subsequent biochemical analyses. In the first set of animals (5 controls, 6 controls + DL- $\alpha$-lipoic acid, 7 diabetics and 7 diabetics + DL- $\alpha$ lipoic acid), one lens from each rat was used for measurements of GSH, oxidized gluathione (GSSG), metabolites (except sorbitol, fructose, and myo-inositol) and adenine nucleotides, and the second lens was used for measurements of sorbitol, fructose, myo-inositol, ascorbate and taurine. In the second set of animals ( 5 controls, 4 diabetics and 8 diabetics + DL- $\alpha$-lipoic acid), both lenses were used for measurements of metabolites and adenine nucleotides only. Blood samples for measurements of glucose were taken from the tail vein the day before killing.

Measurements of metabolites and adenine nucleotides. Lenses were weighed and deproteinized by homogenization with perchloric acid ( $1 \mathrm{ml}$ of $6 \% \mathrm{HCIO}_{4}$ per lens), followed by centrifugation (Sorvall MC $12 \mathrm{~V}$ ). The concentrations of glucose, glucose 6-phosphate (G6P), fructose 6-phosphate (F6P), fructose 1,6-disphosphate (FDP), dihydroxyacetone phosphate (DHAP), 3-phosphoglycerate (3-PG), phosphoenolpyruvate (PEP), pyruvate, lactate, malate, $\alpha$-glycerophosphate $(\alpha-G P)$, ATP, ADP, and AMP were assayed in neutralized extracts (neutralization was done with $\mathrm{K}_{2} \mathrm{CO}_{3} 2 \mathrm{~mol} / \mathrm{l}$ ) of individual lenses spectrofluorometrically (Perkin-Elmer LS-5B, Norwalk, Connecticut, USA) by enzymatic procedures as described [24]. The lower limit for all spectrofluorometric procedures in our study including glucose, sorbitol, fructose, and 
myo-inositol was $0.1 \times 10^{-9} \mathrm{~mol} / \mathrm{l}$. Inorganic phosphate $(\mathrm{Pi})$ concentrations were assayed by a colorimetric procedure with kits from Sigma Diagnostics.

Measurements of sorbitol, fructose, and myo-inositol. Lenses were weighed and homogenized in $0.8 \mathrm{ml} 0.9 \%$ NaCI. A $100 \mu \mathrm{l}$ volume of $0.3 \mathrm{~mol} / \mathrm{l}$ zinc sulphate, and then an equivalent of barium hydroxide, was added to $0.2 \mathrm{ml}$ of homogenate for protein precipitation. The samples were centrifuged at $4000 \times g$ for $10 \mathrm{~min}$ and aliquots of the supernatant were taken for spectrofluorometric measurements of sorbitol, fructose, and myoinositol by enzymatic procedures, using sorbitol dehydrogenase [25], fructose dehydrogenase [26], and myo-inositol dehydrogenase [25], respectively. In brief, the analytical mixture for sorbitol and myo-inositol contained $0.9 \mathrm{ml} 0.5 \mathrm{mmol} / \mathrm{l}$ NAD in $0.1 \mathrm{~mol} / 1$ glycine-NaOH buffer ( $\mathrm{pH} 9.5$ ) and deproteinized extract (for sorbitol, $0.1 \mathrm{ml}$ for control and $0.01 \mathrm{ml}$ plus $0.09 \mathrm{ml} \mathrm{H}_{2} \mathrm{O}$ for diabetic lenses; for myo-inositol, $0.1 \mathrm{ml}$ for both control and diabetic lenses). The reaction was started by addition of approximately $0.8 \mathrm{U}$ of sorbitol dehydrogenase or $0.5 \mathrm{U}$ of $m y o$-inositol dehydrogenase. The analytical mixture for fructose contained $0.9 \mathrm{ml}$ of rezasurin-containing $150 \mathrm{mmo} / \mathrm{l}$ citrate buffer, $\mathrm{pH} 4.5$ (1 aliquote of rezasurin $\left(5 \mathrm{mg}-10 \mathrm{ml} \mathrm{H}_{2} \mathrm{O}\right)$ was mixed with 100 aliquotes of citrate buffer) and deproteinized extract $(0.1 \mathrm{ml}$ for control and $0.05 \mathrm{ml}$ plus $0.05 \mathrm{ml} \mathrm{H}_{2} \mathrm{O}$ for diabetic lenses). The reaction was started by addition of approximately $0.5 \mathrm{U}$ of fructose dehydrogenase.

Measurement of taurine. Lens taurine was measured by reversed phase HPLC (Waters, Milford, Mass., USA) after precolumn derivatization with o-phthalaldehyde [27]. In brief, $0.1 \mathrm{ml}$ of lens homogenate (see Measurements of sorbitol, fructose and myo-inositol) was extracted with $1 \mathrm{ml}$ of $6 \%$ trichloroacetic acid and centrifuged at $4000 \times g$ for $10 \mathrm{~min}$. The supernatants were purified on washed dual-bed, ion-exchange columns (2.5 cm AG 1-X8 100-200 mesh [Bio-Rad, Richmond, California, USA] in the chloride form over $2.5 \mathrm{~cm} \mathrm{AG} \mathrm{50W-}$ X8 200/400 mesh [Bio-Rad] in the hydrogen form) by elution with $2 \mathrm{ml}$ of water and lyophilized. Samples and standards were dissolved in $100 \mu \mathrm{l}$ of water prior to HPLC analysis. Isocratic elution was carried out at a flow rate of $2 \mathrm{ml} / \mathrm{min}$, using $43 \%$ solvent A $\left(0.05 \mathrm{~mol} / 1 \mathrm{NaH}_{2} \mathrm{PO}_{4}, \mathrm{pH} 5.3\right.$ plus $5 \mathrm{~mol} / \mathrm{l}$ $\mathrm{NaOH})$ combined with $57 \%$ solvent B $\left(0.05 \mathrm{~mol} / \mathrm{l} \mathrm{NaH} \mathrm{NO}_{4}\right.$ in $75 \%$ methanol/water). Glutamine, added after ion exchange chromatography, was used as the internal standard.

Measurements of other antioxidants. Concentrations of GSH were assayed in perchloric acid extracts colorimetrically as described [14] and of GSSG spectrofluorometrically by enzymatic procedure. The analytical mixture contained $0.8 \mathrm{ml} 0.1 \mathrm{~mol} / \mathrm{l}$ imidazole buffer ( $\mathrm{pH} 7.6), 0.2 \mathrm{ml}$ of perchloric extract and $0.2-10 \mu \mathrm{mol}$ NADPH. The reaction was started by addition of approximately $0.3 \mathrm{U}$ of glutathione reductase (Type IV, Sigma). Concentration of ascorbate were measured colorimetrically with 2,6-dichlorophenolindophenol [28], after extraction of $0.4 \mathrm{ml}$ of lens homogenate (see Measurements of sorbitol, fructose and myo-inositol) with $5 \%$ metaphosphoric acid. All spectrophotometric measurements $\left(\mathrm{GSH}, \mathrm{P}_{\mathrm{i}}\right.$ and ascorbate) were done using the spectrophotometer Beckman DU 640, (Fullerton, Calif., USA).

Calculations of free cytosolic $N A D^{+}: N A D H$ and $N A D P^{+}: N A D P H$ ratios, mass action ratio of the ATP system, and adenylate energy charge. According to classical publications of Krebs' laboratory [29, 30] and other studies [31], direct measurements of NAD, NADH, NADP and NADPH are not informative in terms of control of metabolism as they do not inform on compartmentalization of nicotinamide nucleotides between cytosol and mitochondria and do not separate free from protein-bound forms (only free fractions determine direction and free-energy changes of dehydrogenase reactions). The same studies proposed an alternative approach with assessment of free $\mathrm{NAD}(\mathrm{P})^{+}: \mathrm{NAD}(\mathrm{P})$ ratios in the cytoplasm and mitochondria by measuring the ratios of the concentrations of the oxidized and reduced metabolites of suitable NAD(P)-linked dehydrogenase systems. Using this approach, free cytosolic $\mathrm{NAD}^{+}: \mathrm{NADH}$ and $\mathrm{NADP}^{+}$:NADPH ratios were calculated from metabolite concentrations and the equilibrium constants of lactate dehydrogenase and malic enzyme as follows [29-31]:

$\frac{\left[\mathrm{NAD}^{+}\right]}{[\mathrm{NADH}]}=\frac{[\text { Pyruvate }]}{[\text { Lactate }]} \times \frac{1}{\mathrm{k}_{1}}$,

where $\mathrm{k}_{1}$ is the equilibrium constant of lactate dehydrogenase $\left(1.11 \times 10^{-4} \mathrm{~mol} / 1[29,31]\right.$.

$\frac{\left[\mathrm{NADP}^{+}\right]}{[\mathrm{NADH}]}=\frac{[\text { Pyruvate }] \times\left[\mathrm{CO}_{2}\right]}{[\text { Malate }]} \times \frac{1}{\mathrm{k}_{2}}$,

where $\mathrm{k}_{2}$ is the equilibrium constant of malic enzyme $\left(3.44 \times 10^{-2} \mathrm{~mol} / \mathrm{l}\right)$ [30] (the $\mathrm{CO}_{2}$ concentration was taken to be $1.16 \mathrm{mmol} / \mathrm{l})$.

Mass action ratio of the ATP system ([ATP $\left.]:[\mathrm{ADP}] \times\left[\mathrm{P}_{\mathrm{i}}\right]\right)$ as a parameter of phosphorylation state of adenine nucleotides [31] and adenylate energy charge $\{[$ ATP + (ADP:2) $]$ :ATP $+\mathrm{ADP}+\mathrm{AMP}]\}$ were calculated from measured concentrations of ATP, ADP, AMP and $\mathrm{P}_{\mathrm{i}}$.

Statistical analysis. The results are expressed as means \pm standard deviation. If the standard deviation for a variable increased substantially with increase of the mean of the variable, the formal analysis was conducted on natural logarithm transformed data to reduce the heterogeneity of variances; otherwise, the analysis was conducted on the observed data. Individual pair-wise comparisons between the experimental groups (controls vs controls + DL- $\alpha$-lipoic acid, controls vs diabetics, diabetics vs diabetics + DL- $\alpha$-lipoic acid, and diabetics + DL- $\alpha-$ lipoic acid vs controls) were evaluated by the Behrens-Fisher two-sided two-sample $t$-test that does not assume equality of variances.

\section{Results}

The body weights were lower in diabetic rats compared with those in control rats $(297.5 \pm 69.7$ vs $439.4 \pm 45.7 \mathrm{~g}, p=0.0004)$. The initial body weights were similar in these two groups $(264.7 \pm 19.5$ and $240.6 \pm 17.8 \mathrm{~g}$, respectively). No significant difference was found between body weights in control and diabetic rats treated with DL- $\alpha$-lipoic acid $(407.6 \pm 50.4$ and $282.3 \pm 55.5 \mathrm{~g}$, respectively) and the corresponding untreated groups.

The lens wet weights were not different among the experimental groups studied (controls: $31.5 \pm 2.2 \mathrm{mg}$, diabetics: $33.2 \pm 4.1$, and diabetics + DL- $\alpha$-lipoic acid: $31.5 \pm 3.6 \mathrm{mg}$ ).

Plasma glucose concentrations were increased about 3.9-fold in diabetic rats compared with those in control rats $(15.9 \pm 2.6$ vs $3.9 \pm 0.3 \mathrm{mmol} / 1, \quad p=$ 
Table 1. Lens glucose, sorbitol, fructose, and $m y o$-inositol concentrations ( $\mu \mathrm{mol} / \mathrm{g}$ wet weight) in control and diabetic rats treated with and without DL- $\alpha$-lipoic acid

\begin{tabular}{|c|c|c|c|c|}
\hline & $\begin{array}{l}\text { Control } \\
(n=5)\end{array}$ & $\begin{array}{l}\text { Control + LA } \\
(n=6)\end{array}$ & $\begin{array}{l}\text { Diabetic } \\
(n=7)\end{array}$ & $\begin{array}{l}\text { Diabetic + LA } \\
(n=7)\end{array}$ \\
\hline Glucose & $1.490 \pm 0.548$ & $1.160 \pm 0.591$ & $5.78 \pm 1.26^{\mathrm{a}}$ & $5.45 \pm 1.50^{\mathrm{a}}$ \\
\hline Sorbitol & $0.683 \pm 0.197$ & $0.536 \pm 0.067$ & $13.38 \pm 3.88^{\mathrm{a}}$ & $11.28 \pm 4.22^{\mathrm{a}}$ \\
\hline Fructose & $0.911 \pm 0.246$ & $0.986 \pm 0.488$ & $5.85 \pm 1.62^{\mathrm{a}}$ & $5.66 \pm 2.25^{\mathrm{b}}$ \\
\hline myo-Inositol & $0.523 \pm 0.102$ & $0.479 \pm 0.075$ & $0.040 \pm 0.029^{a}$ & $0.048 \pm 0.029^{\mathrm{a}}$ \\
\hline
\end{tabular}

LA, DL- $\alpha$-lipoic acid;

a,b Significantly different compared with those in controls $(p<0.0001$ and $<0.001$, respectively)

Table 2. Lens antioxidant status in control and diabetic rats treated with and without DL- $\alpha$-lipoic acid (concentrations of GSH, GSSG, ascorbate, and taurine are expressed in $\mu \mathrm{mol} / \mathrm{g}$ wet weight)

\begin{tabular}{lcccc}
\hline & Control & Control + LA & Diabetic & Diabetic + LA \\
\hline$n$ & 5 & 6 & 7 & 7 \\
GSH & $5.14 \pm 0.52$ & $5.19 \pm 0.64$ & $1.75 \pm 0.52^{\mathrm{a}}$ & $3.45 \pm 1.17^{\mathrm{b}, \mathrm{d}}$ \\
GSSG & $0.225 \pm 0.064$ & $0.226 \pm 0.050$ & $0.328 \pm 0.130$ & $0.264 \pm 0.109$ \\
100GSSG : GSH & $4.41 \pm 1.27$ & $4.37 \pm 0.92$ & $0.94 \pm 7.71^{\mathrm{a}}$ & $7.90 \pm 2.75^{\mathrm{b}, \mathrm{d}}$ \\
Ascorbate & $0.232 \pm 0.045$ & $0.259 \pm 0.071$ & 5 & $0.200 \pm 0.046$ \\
$n$ & 6 & 6 & $1.21 \pm 1.12^{\mathrm{a}}$ & 7 \\
Taurine & $7.38 \pm 1.80$ & $7.26 \pm 0.76$ & $3.21 \pm 2.23^{\mathrm{b}}$ \\
\hline
\end{tabular}

LA, DL- $\alpha$-lipoic acid;

a,b,c Significantly different compared with those in controls $(p<0.0001,<0.01$ and $<0.05$, respectively $)$
${ }^{\mathrm{d}}$ Significantly different compared with those in untreated diabetics $(p<0.01)$
0.0001). DL- $\alpha$-lipoic acid treatment had no effect on plasma glucose concentrations in either control $(4.0 \pm 0.6)$ or diabetic $(16.5 \pm 3.8)$ rats.

Concentrations of lens glucose, sorbitol, and fructose were increased 3.9-fold, 19.6-fold, and 6.4-fold, respectively, in diabetic rats, compared with those in controls and of myo-inositol levels in 6-week diabetic rats depleted to about $8 \%$ of those in controls. None of these variables was affected by DL- $\alpha$-lipoic acid treatment in either control or diabetic rats (Table 1).

Lens GSH, GSSG, and ascorbate concentrations as well as 100GSSG:GSH ratios were similar in control rats treated with and without DL- $\alpha$-lipoic acid (Table 2). Lens GSH, ascorbate, and taurine concentrations in diabetic rats were decreased to $34 \%$, $72 \%$, and $10 \%$ of those in controls. Concentrations of GSSG did not differ in the two groups but 100GSSG:GSH ratio in diabetic rats was increased 4.5-fold. Diabetes-induced depletion of GSH was partially prevented by DL- $\alpha$-lipoic acid treatment. Taurine levels tended to increase although the difference from untreated diabetics did not reach statistical significance $(p=0.068)$. Concentrations of GSSG and ascorbate remained unaffected. The increase in 100GSSG:GSH ratio in diabetic rats was substantially but not completely prevented by DL- $\alpha$-lipoic acid.

The concentrations of the glycolytic intermediates, G6P and F6P, were increased by $67 \%$ and $32 \%$ in the lenses of diabetic rats compared with those in controls. Those of FDP were decreased by $21 \%$ and of DHAP increased by $51 \%$, but those of metabolites of the lower segment of glycolysis, i.e. 3-PG, PEP, and pyruvate were considerably decreased (by 29, 69 and $45 \%$, respectively) in the diabetic rats, and lactate levels were similar in control and diabetic groups. Concentrations of all glycolytic intermediates studied were indistinguishable between control rats treated with and without DL- $\alpha$-lipoic acid. The DL- $\alpha$ lipoic acid treatment of diabetic rats completely prevented the decrease in FDP and 3PG levels. Accumulation of DHAP as well as decrease in pyruvate were partially prevented but PEP tended to increase although the difference with untreated diabetic group did not reach significance $(p=0.055)$. The concentrations of G6P, F6P, and lactate remained unaffected (Table 3).

Lens $\alpha$-GP concentrations in 6-week diabetic rats were increased 5.9-fold $(1.59 \pm 0.20 \mu \mathrm{mol} / \mathrm{g}$ wet weight vs $0.268 \pm 0.046$ in controls, $p<0.0001)$. The increase was partially prevented in diabetic rats treated with DL- $\alpha$-lipoic acid $(0.878 \pm 0.411, p<0.0001$ vs both untreated diabetic and controls). DL- $\alpha$-lipoic acid had no effect on $\alpha$-GP concentrations in control rats $(0.327 \pm 0.076)$.

Lens malate concentrations were similar in control rats treated with and without DL- $\alpha$-lipoic acid $(0.087 \pm 0.014$ and $0.087 \pm 0.016 \mu \mathrm{mol} / \mathrm{g}$ wet weight, respectively). They were substantially depleted in diabetic rats $(0.035 \pm 0.012, p=0.0001$ vs controls $)$. This depletion was partially prevented with DL- $\alpha$-lipoic acid treatment $(0.054 \pm 0.011, p=0.001$ and $=0.0001$ vs untreated diabetics and controls, respectively). 
Table 3. Concentrations of glycolytic intermediates in lenses in control and diabetic rats treated with and without DL- $\alpha$-lipoic acid $(\mu \mathrm{mol} / \mathrm{g}$ wet weight)

\begin{tabular}{lllll}
\hline & Control & Control + LA & Diabetic & Diabetic + LA \\
\hline$n$ & 10 & 6 & 11 & 15 \\
G6P & $0.142 \pm 0.022$ & $0.135 \pm 0.037$ & $0.237 \pm 0.037^{\mathrm{a}}$ & $0.233 \pm 0.035^{\mathrm{a}}$ \\
F6P & $0.069 \pm 0.012$ & $0.071 \pm 0.020$ & $0.091 \pm 0.016^{\mathrm{c}}$ & $0.087 \pm 0.019^{\mathrm{c}}$ \\
FDP & $0.052 \pm 0.003$ & $0.054 \pm 0.007$ & $0.041 \pm 0.005^{\mathrm{a}}$ & $0.056 \pm 0.005^{\mathrm{d}, \mathrm{e}}$ \\
DHAP & $0.045 \pm 0.007$ & $0.047 \pm 0.015$ & $0.068 \pm 0.015^{\mathrm{b}}$ & $0.050 \pm 0.015^{\mathrm{f}}$ \\
$n$ & 11 & 6 & 9 & 14 \\
3-PG & $0.075 \pm 0.006$ & $0.066 \pm 0.013$ & $0.053 \pm 0.008^{\mathrm{a}}$ & $0.076 \pm 0.012^{\mathrm{e}}$ \\
$n$ & 12 & 6 & 10 & 14 \\
PEP & $0.042 \pm 0.016$ & $0.033 \pm 0.012$ & $0.013 \pm 0.007^{\mathrm{a}}$ & $0.018 \pm 0.006^{\mathrm{a}}$ \\
$n$ & 12 & 6 & $0.062 \pm 0.018^{\mathrm{a}}$ & 15 \\
Pyruvate & $0.112 \pm 0.024$ & $0.108 \pm 0.014$ & $8.15 \pm 1.57$ & $0.093 \pm 0.037^{\mathrm{f}}$ \\
Lactate & $7.93 \pm 0.69$ & $8.08 \pm 0.60$ & & $7.69 \pm 1.69$ \\
\hline
\end{tabular}

LA, DL- $\alpha$-lipoic acid;

e,f Significantly different compared with those in untreated diaa,b,c,d Significantly different compared with those in controls ( $p<0.0001,<0.001,<0.01$, and $<0.05$, respectively),

betic groups ( $p<0.0001$ and $<0.01$, respectively)

Table 4. Lens energy status in control and diabetic rats treated with and without DL- $\alpha$-lipoic acid (concentrations of ATP, ADP, AMP, and $\mathrm{P}_{\mathrm{i}}$ are expressed in $\mu \mathrm{mol} / \mathrm{g}$ wet weight)

\begin{tabular}{lcccc}
\hline & $\begin{array}{l}\text { Control } \\
(n=12)\end{array}$ & $\begin{array}{l}\text { Control + LA } \\
(n=6)\end{array}$ & $\begin{array}{l}\text { Diabetic } \\
(n=10)\end{array}$ & $\begin{array}{c}\text { Diabetic + LA } \\
(n=15)\end{array}$ \\
\hline ATP & $2.04 \pm 0.30$ & $2.17 \pm 0.19$ & $1.56 \pm 0.34^{\mathrm{c}}$ & $1.95 \pm 0.28^{\mathrm{g}}$ \\
ADP & $0.285 \pm 0.043$ & $0.297 \pm 0.064$ & $0.369 \pm 0.050^{\mathrm{b}}$ & $0.312 \pm 0.050^{\mathrm{g}}$ \\
AMP & $0.084 \pm 0.019$ & $0.075 \pm 0.012$ & $0.134 \pm 0.020^{\mathrm{a}}$ & $0.091 \pm 0.010^{\mathrm{e}}$ \\
ATP : ADP & $7.22 \pm 0.87$ & $7.51 \pm 1.41$ & $4.31 \pm 1.06^{\mathrm{a}}$ & $6.29 \pm 0.88^{\mathrm{d}, \mathrm{h}}$ \\
ATP + ADP + AMP & $2.414 \pm 0.347$ & $2.537 \pm 0.238$ & $2.067 \pm 0.344^{\mathrm{d}}$ & $2.348 \pm 0.318^{\mathrm{h}}$ \\
Adenylate charge & $0.91 \pm 0.01$ & $0.91 \pm 0.01$ & $0.84 \pm 0.03^{\mathrm{a}}$ & $0.89 \pm 0.01^{\mathrm{a}, \mathrm{e}}$ \\
P $_{\mathrm{i}}$ & $2.55 \pm 0.29$ & $3.10 \pm 0.44^{\mathrm{b}}$ & $2.85 \pm 0.22^{\mathrm{d}}$ & $2.92 \pm 0.26^{\mathrm{c}}$ \\
ATP : ADP $\times \mathrm{P}_{\mathrm{i}}$ & $2.86 \pm 0.41$ & $2.48 \pm 0.66$ & $1.52 \pm 0.37^{\mathrm{a}}$ & $2.17 \pm 0.33^{\mathrm{a}, \mathrm{f}}$ \\
\hline
\end{tabular}

LA, DL- $\alpha$-lipoic acid;

a,b,c,d Significantly different from those in controls $(p<0.0001$, $<0.001,<0.01$, and $<0.05$, respectively)

Free cytosolic $\mathrm{NAD}^{+}: \mathrm{NADH}$ ratios were similar in control rats treated with and without DL- $\alpha$-lipoic acid $(126.7 \pm 23.4$ and $120.1 \pm 13.8)$ and considerably reduced in diabetic rats $(69.7 \pm 17.6$ vs controls, $p<0.0001)$. This reduction was prevented by DL- $\alpha$-lipoic acid treatment $(108.7 \pm 30.0, p<0.0005$ and $=0.088$ vs untreated diabetics and controls, respectively).

Free cytosolic $\mathrm{NADP}^{+}$:NADPH ratios were increased in diabetic rats vs those in controls $(0.061 \pm 0.010$ and $0.043 \pm 0.005, p<0.0001)$. DL- $\alpha$-lipoic acid treatment had no effect on free cytosolic $\mathrm{NADP}^{+}: \mathrm{NADPH}$ ratios in either control $(0.043 \pm$ $0.008)$ or diabetic $(0.054 \pm 0.011)$ rats.

The concentrations of ATP, ADP, AMP as well as ATP:ADP ratio, total adenine nucleotide content, adenylate charge, and mass action ratio of the ATP system were similar in control rats treated with and without DL- $\alpha$-lipoic acid but $\mathrm{P}_{\mathrm{i}}$ levels were slightly higher in DL- $\alpha$-lipoic acid-treated group $(p<0.02)$. In diabetic rats ATP concentrations were $24 \%$ lower than in controls but ADP, AMP, and $\mathrm{P}_{\mathrm{i}}$ were increased. The total adenine nucleotide concentration e,f,g,h Significantly different from those in untreated diabetic rats $(p<0.0001,<0.001,<0.01$, and $<0.05$, respectively)

as well as ATP:ADP, ATP:ADP $\times \mathrm{P}_{\mathrm{i}}$ and adenylate energy charge were reduced in diabetic rats compared with controls. DL- $\alpha$-lipoic acid treatment prevented the decrease in ATP and total adenine nucleotide as well as the increase in ADP and AMP. The decrease in ATP:ADP ratio, mass action ratio of the ATP system, and adenylate energy charge were partially prevented while $\mathrm{P}_{\mathrm{i}}$ concentrations remained unaffected (Table 4).

\section{Discussion}

The absence of any difference in either body weights or blood glucose concentrations between the DL- $\alpha$-lipoic acid-treated rats and those untreated is consistent with other findings [32].

The diabetes-induced increase in lens glucose, sorbitol, and fructose agrees with earlier publications $[18,33]$ although the accumulation of sorbitol and fructose in the diabetic group in our study was lower compared with others where measurements of the sorbitol pathway intermediates were done (probably, 
due to lower blood glucose concentrations: $15.9 \mathrm{mmol} / \mathrm{l}$ in our study vs $25 \mathrm{mmol} / \mathrm{l}$ and higher in the others $[33,34])$. It has been reported that $\alpha$-lipoic acid stimulates glucose transport in muscle [35], as well as in peripheral nerve with resulting increases of nerve glucose, sorbitol and fructose [36]. Despite glucose transporter 1 (GLUT 1) (the translocation of which to the plasma membrane in the muscle is facilitated with DL- $\alpha$-lipoic acid treatment [35]) being the most abundant glucose transporter in both lens and peripheral nerve, we found no difference in lens glucose, sorbitol and fructose concentrations in the DL- $\alpha$ lipoic acid-treated control and diabetic rats and the corresponding untreated groups. These findings can probably be explained by low concentrations of glucose transporters in rat lenses as well as by their predominant localization in the nucleus and low density in the outer regions such as epithelium and cortex [37].

The depletion of myo-inositol in diabetic rats is consistent with the dramatic intralenticular accumulation of sorbitol and agrees with previous reports $[18,33]$. The depletion of myo-inositol is considered to result from both osmotically-mediated decrease in $\left(\mathrm{Na}^{+}\right)$-myo-inositol uptake and increase in myo-inositol efflux [38].

The diabetes-induced decrease in lens GSH concentrations is consistent with previous studies [14, 39]. The loss of GSH has been suggested to be a result of impaired ability of the lens to concentrate amino acids required for GSH biosynthesis coupled to faster GSH efflux under hyperosmotic conditions, rather than inhibition of glutathione reductase or depletion of NADPH due to increased flux through aldose reductase [14]. This conclusion is supported by 1) a further decrease in lens GSH levels in diabetic rats treated with sorbitol dehydrogenase inhibitor (that increases lens sorbitol concentrations about twofold over those in untreated diabetics) $[7,40] ; 2)$ the absence of a reciprocal increase of GSSG concentrations in concert with the decrease in GSH ([38] and in the present study). In addition, it has been suggested that the fall in GSH in diabetic rats can be further aggravated by the decrease of ATP (which is required for de novo synthesis of GSH, both at the $\gamma$-glutamyl cysteine synthetase and glutathione synthetase steps [41]. Treatment with DL- $\alpha$-lipoic acid partially prevented the diabetes-induced decrease in lens GSH concentrations which agrees with the studies on BSO-treated rats [23] and with findings in diabetic nerve [32]. The prevention of GSH depletion by DL$\alpha$-lipoic acid in diabetes and in other models of oxidative stress can not be attributed to the corresponding changes in GSSG concentrations because the decrease in GSSG with DL- $\alpha$-lipoic acid treatment is either very minor (compared with the increase in GSH) [32] or absent [23], and in this study) and the decrease in GSH was substantially prevented by both racemic $\alpha$-lipoic acid and its R-enantiomer [23].
Lens ascorbate concentrations in our study are comparable to those obtained by HPLC [39]. The diabetes-induced decrease in lens ascorbate agrees with other reports $[39,43]$. The failure to prevent the diabetes-induced decrease in lens ascorbate by DL- $\alpha$ lipoic acid in our study (vs complete prevention of BSO-induced ascorbate decrease by both racemic $\alpha$ lipoic acid and its R-enantiomer [23]) indicates that the contribution of a redox cycling mechanism to the diabetes-induced decrease in ascorbate concentrations is fairly minor, and another (potentially osmotic [16]) factor could be responsible for ascorbate depletion in the lens under diabetic conditions.

Lens taurine concentrations in control rats in our study are higher compared with those of two previous reports $[15,43]$ but are in agreement with another [44] where taurine levels in rat lens exceeded those of GSH. Although taurine is the most abundant free amino acid in the lens $[43,44]$ its uptake by the lens is very low [45] which implies an endogenous taurine-synthesizing mechanism probably from cysteine and methionine. No information on the activity of cysteine sulphinate decarboxylase, the taurine-forming enzyme, in the lens is available. The observed diabetes-related depletion of taurine agrees with other findings [15], and is considered to be a result of osmotic compensation in response to intralenticular accumulation of sorbitol. A tendency towards amelioration of taurine depletion with DL- $\alpha$-lipoic acid treatment concurs with the ability of the drug to restore other antioxidants in other models of oxidative stress [23]. The effect of DL- $\alpha$-lipoic acid treatment on lens taurine levels seems not to be osmotically mediated as neither sorbitol nor myo-inositol concentrations were affected.

The pattern of glycolytic intermediates in lens in diabetic rats compared with controls (increase in G6P and F6P, decrease in FDP, increase in DHAP, decrease in 3-PG, PEP, pyruvate, no difference in lactate) suggests inhibition of glycolysis, with the sites of regulation at phosphofructokinase, glyceraldehyde 3phosphate dehydrogenase, enolase, and pyruvate kinase. The conclusion that glycolysis is inhibited at the stage of glyceraldehyde 3-phosphate dehydrogenase is supported by the demonstration that this enzyme is a target for oxidative damage [19] and by that of a 5.9-fold increase in $\alpha$-GP which can be converted both to diacylglycerol and its metabolites in the lens [46]. The observed diabetes-induced accumulation of $\alpha$-GP in the lens accords with other reports $[34,40]$, and is consistent with the decreased free cytosolic NAD ${ }^{+}$NADH ratio which reflects the shift in equilibrium of $\alpha$-GP dehydrogenase reaction towards the formation of $\alpha-G P$. A complete prevention of the diabetes-induced increase in lens $\alpha$-GP concentrations by an aldose reductase inhibitor (sorbinil), and only partial ( $\sim 50 \%$ ) prevention by a sorbitol dehydrogenase inhibitor (CP-166,572) [40] indi- 
cates that in addition to a polyol pathway flux-linked change in NAD ${ }^{+}: \mathrm{NADH}$ ratio (which is in equilibrium with the ratio of DHAP to $\alpha$-GP [29]), other aldose-reductase mediated mechanism(s) contribute to a rise in lens $\alpha$-GP levels under diabetic conditions. One of these putative mechanisms could be an increased reduction of GA3P to $\alpha$-GP by aldose reductase $[46,47]$. Others could be linked to aldose-reductase mediated oxidative stress which inhibits the flux through glyceraldehyde 3-phosphate dehydrogenase (and hence the lower segment of glycolysis, resulting in a decrease in cytosolic ATP:ADP $\times \mathrm{P}_{\mathrm{i}}$, and in $\left.\mathrm{NAD}^{+}: \mathrm{NADH}[31]\right)$, and may also impact on the activity of cytosolic DT diaphorase etc. The partial prevention of the diabetes-induced increase in DHAP and $\alpha-G P$, complete prevention of the decrease in 3$\mathrm{PG}$ and amelioration of pyruvate concentrations and $\mathrm{NAD}^{+}: \mathrm{NADH}$ ratios with DL- $\alpha$-lipoic acid treatment in this study supports the contribution of oxidative stress to diabetes-induced inhibition of glycolysis, accumulation of $\alpha-\mathrm{GP}$ and the shift towards a more reduced state of free cytosolic NAD-couple. At the same time, a complete prevention of the decrease in FDP in DL- $\alpha$-lipoic acid treated diabetic rats [48] points to an additional beneficial effect of the drug on glucose utilization at the level of phosphofructokinase. Prevention of the diabetes-induced decrease in FDP by structurally different ARIs and, on the contrary, further depletion of FDP by sorbitol dehydrogenase inhibitor [40] points to an osmotic mechanism in the down-regulation of phosphofructokinase and suggests that amelioration of osmotically-induced oxidative stress rather than "metabolic" effects of DL- $\alpha$ lipoic acid by decreasing intracellular citrate [48] could prevent the diabetes associated fall in lens FDP concentrations.

Note that, in addition to a "direct" cytosolic effect of DL- $\alpha$-lipoic acid on free cytosolic $\mathrm{NAD}^{+}: \mathrm{NADH}$ ratio in the diabetic lens DL- $\alpha$-lipoic acid can "indirectly" affect cytosolic reducing equivalent homeostasis by reduction of $\alpha$-lipoate to dihydrolipoate by mitochondrial dihydrolipoamide dehydrogenase [49] (with a resulting decrease in mitochondrial NADH and stimulation of NADH transfer from cytosol to mitochondria). The ability of $\alpha$-lipoic acid to decrease both lactate:pyruvate and total NADH:NAD ${ }^{+}$ ratios under normoglycaemic conditions has been shown in cell culture experiments [49], however, in our in vivo study, DL- $\alpha$-lipoic acid seems not to affect free cytosolic $\mathrm{NAD}^{+} / \mathrm{NADH}$ ratios (calculated for whole lenses) of control rats. Both in vitro and in vivo studies suggest that "direct" cytosolic effects of DL- $\alpha$-lipoic acid are primarily responsible for amelioration of cytosplasmic NAD-redox status in the whole diabetic lens, although "indirect" mitochondrial effects probably prevail in the equatorial subcapsular cortex which is rich in mitochondria and has a critical role in glucose mediated cataractogenesis [20].
In contrast to free cytosolic $\mathrm{NAD}^{+}: \mathrm{NADH}$ ratios, lens free cytosolic $\mathrm{NADP}^{+}$:NADPH ratios were increased in diabetic rats compared with controls. This agrees with the depletion of NADPH levels [14] as well as with the observations in a galactose model [50] and favours activation of the pentose phosphate pathway regenerating reducing equivalents (NAD$\mathrm{PH})$ for aldose reductase [51]. The failure of DL- $\alpha$-lipoic acid to affect the redox state of free cytosolic NADP-couple is consistent with the absence of changes in sorbitol pathway metabolites, and implies a similar rate of use of NADPH by aldose reductase in DL- $\alpha$-lipoic acid treated and untreated groups.

The decrease in the glycolytic flux and free cytosolic $\mathrm{NAD}^{+}: \mathrm{NADH}$ ratios accords with changes in the adenine nucleotide system and imply the impairment of energy metabolism in the lens of diabetic rats. The decrease in the mass-action ratio of the ATP system and adenylate energy charge indicate a limited availability of high energy phosphates for metabolic and functional needs. That the decrease compared with controls in ATP concentrations in diabetic rats substantially exceeds the increase in ADP and AMP concentrations is in line with the previous observation of a complete prevention of diabetes-induced changes in lens adenine nucleotide system by an aldose reductase inhibitor compared with further exacerbation of energy deficiency by sorbitol dehydrogenase inhibitor [40] and indicates the role of osmotic stress in the impairment of lens energy status under diabetic conditions. Prevention of diabetes-induced changes in lens adenine nucleotide system by both DL- $\alpha$-lipoic acid and by structurally different ARIs [40] suggests that polyol associated osmotic stress can impair lens energy metabolism via oxidative stress. In addition to glycolysis, oxidative stress affects the redox state of coenzyme Q [52], which leads to inhibition of mitochondrial oxidation coupled to biosynthesis of ATP. Studies in other models of oxidative stress indicate that lipoic acid counteracts those changes. Although it is known that in vitro $\mathrm{R}$-lipoic acid activates the pyruvate dehydrogenase (PDH) complex [54], it is not clear if this mechanism contributes to the amelioration of lens energy status.

In conclusion, diabetes-induced changes in lens intermediary and energy metabolism are substantially prevented by antioxidant DL- $\alpha$-lipoic acid which could thus help to avoid oxidative stress to the lens and thereby possibly diabetes-associated cataract formation.

Acknowledgements. The authors thank Dr. M. B. Brown for statistical analysis of the data, D. L. VanHeyningen for taking taurine measurements and L. Beyer and J. Masterson for expert technical assistance. 


\section{References}

1. Klein R, Klein BEK (1995) Vision Disorders in Diabetes. In: National Institute of Health - National Institute of Diabetes and Kidney Diseases, NIH Publication No.95-1468 (eds) Diabetes in America, 2nd edition, pp 293-338

2. Kinoshita JH, Merola LO, Satoh K, Dikmak E (1962) Osmotic changes caused by the accumulation of dulcitol in the lenses of rats fed with galactose. Nature 194: 10851087

3. Dvornik E, Simard-Duquesne N, Krami M et al. (1973) Polyol accumulation in galactosemic and diabetic rats: control by an aldose reductase inhibitor. Science 182: $1146-1148$

4. Kador PF, Akagi Y, Kinoshita JH (1985) Diabetic cataracts in animal models: prevention and reversibility with aldose reductase inhibitors. Diabet Med 2: 194-196

5. Chylack LT Jr, Henriques HF, Tung WH (1979) Inhibition of sorbitol production in human lenses by an aldose reductase inhibitor. Doc Ophthalmol Proc Series 18: 65-75

6. Varma SD, Kinoshita JH (1974) The absence of cataracts in mice with congenital hyperglycemia. Exp Eye Res 19: 577-582

7. Geissen K, Utz R, Grotsch H, Lang J, Nimmesgern $\mathrm{H}$ (1994) Sorbitol-accumulating Pyrimidine Derivatives. Arzneimittelforschung 44: 1032-1043

8. Lee AYW, Chung SK, Chung SM (1995) Demostration that polyol accumulation is responsible for diabetic cataracts by the use of transgenic mice expressing the aldose reductase gene in the lens. Proc Natl Acad Sci USA 92: 2780-2784

9. Robison WG Jr, Jacot JL, Glover LP, Feld LG (1996) Roles of aldose reductase and glycation in cataracts. Invest Ophthalmol Vis Sci 37:S888 (Abstract)

10. Spector A (1995) Oxidative stress-induced cataract: mechanism of action. FASEB J 9: 1173-1182

11. Bron AJ, Sparrow J, Brown NA, Harding JJ, Blakytny R (1993) The lens in diabetes. Eye 7: 260-275

12. Jones RH, Gronboek H, Kunjara S, Flyvbjerg A (1995) Effect of diabetes and dietary ubiquinone supplementation on the post-translational modification of rat lens beta $\mathrm{L}$ crystallin. Biochem Mol Med 55: 96-104

13. Trevithick JR, Linklater HA, Mitton KP, Dzialoszynski T, Sanford SE (1989) Modelling cortical cataractogenesis: IX. Activity of vitamin E and esters in preventing cataracts and gamma-crystallin leakage from lenses in diabetic rats. Ann N Y Acad Sci 570: 358-371

14. Lou MF, Dickerson JE Jr, Garadi R, York BM Jr (1988) Glutathione depletion in the lens of galactosemic and diabetic rats. Exp Eye Res 46: 517-530

15. Malone JI, Lowitt S, Cook WR (1990) Nonosmotic diabetic cataracts. Pediatr Res 27: 293-296

16. Mitton KP, Dzialoszynski T, Sanford SE, Trevithick JR (1994) Multiple antioxidant deficit in diabetic rat lens: a result of osmotic compensation? Invest Ophthalmol Vis Sci 35: 1570(Abstract)

17. Hothersal JS, Muirhead RP, Taylaur CE, Kunjara S, McLean P(1993) Changes in Uridine Nucleotides and Uridine Nucleotide Sugars in Diabetic Rat Lens: Implications in Membrane Glycoprotein Formation. Biochem Med Metab Biol 50: 292-300

18. Dvornik D(1987) Aldose reductase inhibition. An approach to the prevention of diabetic complications. McGraw Hill, New York

19. Spector A, Wang GM, Wang RR, Garner WH, Moll H (1993) The prevention of cataract caused by oxidative stress in cultured rat lenses. $1 . \mathrm{H}_{2} \mathrm{O}_{2}$ and photochemically induced cataract. Curr Eye Res 12: 163-179
20. Kilic F, Handelman GJ, Serbinova E, Packer L, Trevithick JR (1995) Modelling cortical cataractogenesis 17: in vitro effects of $\alpha$-lipoic acid on glucose-induced lens membrane damage, a model of diabetic cataractogenesis. Biochem Mol Biol Int 37: 361-370

21. Scott BC, Aruoma OI, Evans PJ et al. (1994) Lipoic and dihydrolipoic acids as antioxidants. A critical evaluation. Free Radic Res 20: 119-133

22. Packer L, Witt EH, Trischler HJ (1995) $\alpha$-Lipoic acid as a biological antioxidant. Free Radic Biol Med 19: 227-250

23. Maitra I, Serbinova E, Trischler HJ, Packer L (1996) Stereospecific effects of R-lipoic acid on buthionine sulfoximine-induced cataract formation in newborn rats. Biochem Biophys Res Commun 221: 422-429

24. Lowry OH, Passonneau JV (1972) A Flexible System of Enzymatic Analysis, Academic Press, Orlando

25. Bergmeyer HU (1974). Methods of Enzymatic Analysis, Verlag Chemie, Weinheim

26. Holmes EW (1997) Coupled enzymatic assay for the determination of sucrose. Anal Biochem 244: 103-109

27. Jones, BN, S Paabo, S Stein (1981) Amino acid analysis and enzymatic sequence determination of peptides by an improved 0 -phthaldialdehyde precolumn labeling procedure. J Liq Chromat 4: 565-586

28. Matsuda H, Giblin FJ, Reddy VN (1981) The effect of X-irradiation on cation transport in rabbit lens. Exp Eye Res 33: 253-265

29. Williamson DH, Lund P, Krebs HA (1967) The Redox State of Free Nicotinamide-Adenine Dinucleotide in the Cytoplasm and Mitochondria of Rat Liver Biochem J 103: 514-527

30. Veech RL, Eggleston LV, Krebs HA (1969) The redox state of free nicotinamide-adenine nucleotide phosphate in the cytoplasm of rat liver. Biochem J 115: 609-619

31. Masuda T, Dobson GP, Veech RL (1990) The Gibbs-Donnan Near-equilibrium System of Heart. J Biol Chem 265: 20321-20334

32. Nagamatsu M, Nickander KK, Schmelzer JD et al. (1995) Lipoic Acid Improves Nerve Blood Flow, Reduces Oxidative Stress, and Improves Distal Nerve Conduction in Experimental Diabetic Neuropathy. Diabetes Care 18: $1160-1167$

33. Cameron NE, Cotter MA, Basso M, Hohman TC (1997) Comparison of the effects of inhibitors of aldose reductase and sorbitol dehydrogenase on neurovascular function, nerve conduction and tissue polyol pathway metabolites in streptozotocin-diabetic rats. Diabetologia 40: 271-281

34. Gonzalez AM, Sochor M, McLean P (1983) The Effect of an Aldose Reductase Inhibitor (Sorbinil) on the Level of Metabolites in Lenses of Diabetic Rats. Diabetes 32: 482-485

35. Bashan N, Burdett E, Gum A, Klip A (1993) Effect of Thioctic Acid on Glucose Transport. In: Gries FA, Wessel $\mathrm{K}$ (eds) The role of anti-oxidants in Diabetes mellitus - Oxygen radicals and anti-oxidants in Diabetes. pmi VerlagGruppe, Frankfurt am Main, pp 221-226

36. Low PA, Yao JK, Kishi Y et al. (1997) Peripheral nerve energy metabolism in experimental diabetic neuropathy. Neurosci Res Commun 21: 49-56

37. Kaulen P, Kahle G, Keller K, Wollensak J (1991) Autoradiographic mapping of the glucose transporter with cytochalasin B in the mammalian eye. Invest Ophthalmol Vis Sci 32: 1903-1911

38. Reeves RE, Cammarata PR (1996) Osmoregulatory alterations in myo-inositol uptake by bovine lens epithelial cells. Part 5. Mechanisms of the myo-inositol efflux pathway. Invest Ophthalmol Vis Sci 37: 619-629 
39. Mitton KP, Trevithick JR (1994) High-performance liquid chromatography-electrochemical detection of antioxidants in vertebrate lens: glutathione, tocopherol, and ascorbate. Methods Enzymol 233: 523-539

40. Obrosova I, Burgan J, Ostrow E, Oates P (1997) Evaluation of structurally different ARIs vs SDI on diabetes-induced changes in lens metabolism. Invest Ophthalmol Vis Sci 38:S1171(Abstract)

41. Hothersall JS, Taylaur CE, McLean P (1988) Antioxidant Status in an in Vitro Model for Hyperglycemic Lens Cataract Formation: Effect of Aldose Reductase Inhibitor Statil. Biochem Med Metab Biol 40: 109-117

42. Mitton KP, Dzialoszynski T, Sanford SE, Trevithick JR (1997) Cysteine and ascorbate loss in the diabetic rat lens prior to hydration changes. Curr Eye Res 16: 564-571

43. Heinamaki AA, Muhonen ASH, Piha RS (1986) Taurine and other free amino acids in the retina, vitreous, lens, iris-ciliary body, and cornea of the rat eye. Neurochem Res 11: 535-542

44. Reddy DVN (1968) Distribution of free amino acids and related compounds in ocular fluids, lens and plasma of various animals. Invest Ophthalmol 6: 478-483

45. Baskin SI, Cohn EM, Kocsis JJ (1976) Taurine changes in visual tissues with age. In: Huxtable $\mathrm{R}$ and Barbeau A(eds) Taurine, Raven Press, New York, pp 201-208

46. Vivekanandan S, Lou MF (1989) Evidence for the presence of phosphoinositide cycle and its involvement in cellular signal transduction in the rabbit lens. Curr Eye Res 8: 101-111

47. Obrosova I, Oates P, Nakano T, Petrash JM (1996) Glycolytic pathway, redox state of NAD-couples and energy me- tabolism in lens in rats with short-term streptozotocin diabetes. Diabetes 45 [Suppl 2]:195A(Abstract)

48. Singh HPP, Bowman RH (1970) Effect of DL- $\alpha$-lipoic acid on the citrate concentration and phosphofructokinase activity of perfused hearts from normal and diabetic rats. Biochem Biophys Res Commun 41: 555-561

49. Roy S, Sen CK, Trischler HJ, Packer L (1997) Modulation of cellular reducing equivalent homeostasis by $\alpha$-lipoic acid. Mechanisms and implications for diabetes and ischemic injury. Biochem Pharmacol 53: 393-399

50. Obrosova I, Faller A, Burgan J, Ostrow E, Williamson J (1997) Glycolytic pathway, redox state of NAD(P)-couples and energy metabolism in lens in galactose-fed rats: effect of an aldose reductase inhibitor Curr Eye Res 16: 34-43

51. Holten D, Proscal D, Chang HL (1976) Regulation of pentose pathway dehydrogenases by $\mathrm{NADP}^{+} / \mathrm{NADPH}$ ratios. Biochem Biophys Res Commun 68: 436-441

52. Gotz ME, Dirr A, Burger R et al. (1994) Effect of lipoic acid on redox state of coenzyme $\mathrm{Q}$ in mice treated with 1 methyl-4-phenyl-1,2,3,6-tetrahydropyridine and diethyldithiocarbamate. Eur J Pharmacol 266: 291-300

53. Schonheit K, Gille L, Nohl H (1995) Effect of alpha-lipoic acid and dihydrolipoic acid on ischemia/reperfusion injury of the heart and heart mitochondria. Biochim Biophys Acta 1271: 335-342

54. Loffelhardt S, Bonaventura C, Locher M, Borbe HO, Bisswanger H (1995) Interaction of alpha-lipoic acid enantiomers and homologues with the enzyme components of the mammalian pyruvate dehydrogenase complex. Biochem Pharmacol 50: 637-646 